\title{
Design of a Five-in-one Experiment Teaching System of Economics and Management
}

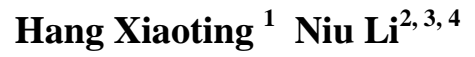 \\ ${ }^{1}$ School of Economics and Management, Beihang University, Beijing, 100191, China \\ ${ }^{2}$ School of Information Resource Management, Renmin University of China, Beijing, 100872, China \\ ${ }^{3}$ Research Center for Humanistic Beijing, Renmin University of China, Beijing, 100872, China \\ ${ }^{4}$ Key Laboratory of Ministry of Education for Data Engineering and Knowledge Engineering, Renmin University of China, \\ Beijing, 100872, China
}

\begin{abstract}
Aimed at cultivating economics and management talents with high quality, this paper builds an experimental teaching system in economics and management, designs a five-in-one framework of multi-dimensional integration in the economics and management of experimental teaching, and innovates methods of experimental teaching with diversification and forms of cross-border experiment teaching, builds the experiment teaching platform of "integration of teaching and research," as well as perfecting the guarantee system of experiment teaching management, thus reforming and innovating the training mode for professional talents in economics and management. What's more important, the experimental teaching system highlights the integration of knowledge in varied disciplines, the cultivation of students' innovative and comprehensive ability; the system also realizes the combination of students' self-study and teachers' guidance, of the professional knowledge learning and relevant knowledge learning, and of theory and practice.
\end{abstract}

Keywords: experiment teaching; economics and management; system design

\section{Introduction}

Experiment teaching is a kind of practical teaching activities to realize the construction of knowledge, enhance ability, and improve the quality in controllable conditions. Experiment teaching plays an important part in high education, which together with practice teaching constitutes the integrated system of talent cultivation. Due to the particularity of the economics and management experiment, the experiment teaching is of great importance to the training of economics and management talents.

First of all, the experiment teaching is an effective method of fostering economics and management professional talents. Experiment teaching can provide students with a good professional education and professional skill training, and at the same time, can achieve a systematic understanding and cognition of economics and management professional knowledge, professional activities, and related professional knowledge.
Finally it helps setting up a training platform of cultivating compound economics and management talents on the basis of modern education technology.

Secondly, experiment teaching breaks the time and space limits in the economics and management practice teaching activity. Because the enterprise needs to keep trade secrets, interns can't learn the operation process deeply and completely. As a result, they gain little in the use of the professional knowledge and the exercise of professional skills. Experiment teaching enables the economics and management practice teaching activities to break the time and space limits, fundamentally creating the conditions of getting rid of its former predicament.

Finally, the experiment teaching shortens the training period of the economics and management professionals. In traditional training mode, a majority of students can't get used to the work in a short time. They usually go through a long period of adaptation. The experiment teaching, can not only help students build up an appropriate knowledge structure, but also improve their practice ability of economics and management. Experiment teaching is undoubtedly a shortcut to train economics and management professionals efficiently.

Therefore, it is of great theory value to supplement and perfect our country's higher education theory system, and the system should include several factors which are as follows: studying economics and management experiment teaching systematically, and integrating the experimental course framework, the experiment teaching methods, and the experiment teaching organization, the teaching resources and the platform, and the security system. It is also of great practice value for colleges and universities to cultivate qualified economics and management talents to meet the needs of social and academic requirements.

\section{Construction of a Five-in-one Experiment Teaching System in Economics and management}

\subsection{Analysis of present economics and management experiment teaching in our country}

Since the experiment teaching of economics and management in China develops late, there are still some problems and challenges in the process of teaching. 
First of all, the experiment teaching is not systematic to form a complete framework. It expounds in three aspects: the laboratory construction and experiment teaching do not match, resources allocation is unreasonable, and the experiment theory teaching do not come up with the social practice.

Secondly, the content of experiment teaching is unreasonable. For example, the teaching gives priority to the verification while the experience comprehensiveness, and innovation is comparatively less. Besides, the content neither reflects China's advanced management practices and economics and management academic, nor can stimulate students' interest.

Thirdly, the ideas and methods of experiment teaching are not advanced, which expounds in the teaching methods - students just record whatever the teacher says, and the teacher usually refer to a prepared example; ignoring students' individuality, teachers instruct students in the same mode and there is a lack of teaching aids.

Fourth, the experimental teaching platform and the supporting system are not sound. To be specific, the management of laboratory and of experimental teaching is not powerful, the mechanism not sound, and the responsibility not clear. Besides, teaching faculty and experiment funds are inadequate, and the variety and the number of large equipment insufficient. With all the above limitations, students may grasp systematic basic knowledge and operation disciplines; but at the same time, students may the lack vitality, which is unfavorable to the cultivation of students' comprehensive ability and innovative ability.

\subsection{Design of five-in-one experiment teaching system in economics and management}

To solve the problems existing in the experimental teaching of economics and management in China, this paper builds an experimental teaching system for the sake of economics and management, which bases on the modern education concept, education method, and education technology, and which aims at cultivating high-quality economics and management talents. What's more, the article also innovates experimental teaching methods and organizational forms, constructs experimental teaching platform, improve the guarantee system of experimental teaching management, thus realizing the reform and innovation of management professional talent training. Experimental teaching system of economics and management is shown in figure 1 .

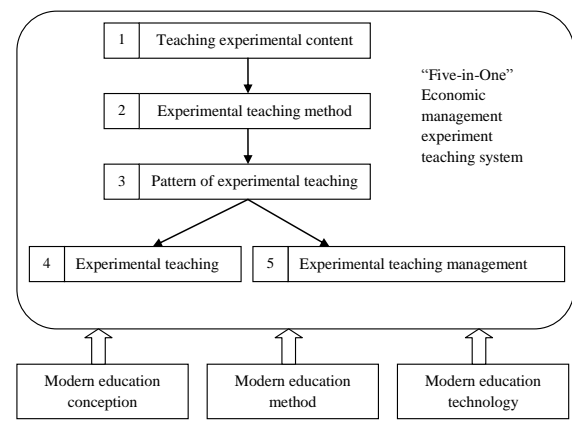

Fig. 1: Experiment teaching system in economics and management.

\section{Construction of Economics and Management Experiment Teaching Platform and Management Assurance System}

It is necessary to establish the experiment teaching platform which can support the contents of experimental curriculum to ensure the smooth progress of experimental teaching, as well as the perfect management assurance system and regulatory framework.

\subsection{Design of five-in-one experiment teaching system in economics and management}

The establishment of economics and management experiment teaching platform needs the base of existing research laboratories. It is necessary to take full advantage of the existing experimental platform and experimental facility design platform which incorporates scientificresearch into teaching practice. This will facilitate the development of both innovation and comprehensive abilities. Secondly, the hardware and software of experimental platforms supply the process of experimental teaching with material insurance, as a result of the fact that the economics and management experiments are usually based on the information technology. As a multifunctional and open hardware platform of experimental teaching, the platform should be characterized by better practicability and adaptability. On the basis of satisfying the teaching need, guaranteeing the resource sharing and advanced technology, the experimental platform is required to realize the economic rationality of its construction cost by means of high technology and informatization. Meanwhile, it is feasible to build the experimental platform through other means, such as independent development by teachers, import from other schools, donation from enterprises, coconstruction between school and enterprise.

\section{2. teaching management assurance system of economics and management experiments}

\section{- opening operational mechanism of experimental} teaching platform

The platform of economics and management experiments needs the opening management mode with the support of 
information technology. It should follow the guidelines such as catering for all, teaching students in accordance of their aptitude and multi tediousness. At the same time, it ought to implement the operation method open all year around. The platform needs to realize the opening mechanisms including course reservation, all day access and experimental project reservation, and to establish relevant system for the safe, stable and efficient opening operation of the base. Simultaneously, the resource allocation and benefit assessment systems for the experimental teaching platform should be established.

\section{- Experimental teaching documents}

One major focus is on establishing and improving the basic documents like experiment teaching outlines, experiment guidebooks, lab reports etc., to construct experimental teaching systems. The standards, contents and forms should be designed according to the different experimental type, for instance, demonstrative experiments, validation experiments, experiential experiments, designing and research experiments, and comprehensive economics and management experiments and etc., because of the fact that the distinction is significant between the economics and management experiments and the traditional engineering experiments.

\section{- Quality evaluation and monitoring systems for experimental teaching}

It is difficult to estimate the teaching quality of economics and management experiments through traditional experimental evaluation criteria such as time and data, because most of them are demonstrative, experiential and comprehensive experiments. As a result, explicit evaluation criteria with guidance and maneuverability should be set up to satisfy the teaching quality evaluation need of the economics and management experiments, from two aspects of evaluations from experts and students, according to different experiment types and the time nodes like during and after the experiments. The feedback mechanism after the experimental teaching evaluation is also needed.

\section{Conclusion}

With purposes of cultivating high-quality economics and management talents, this paper first builds a five-in-one experimental teaching system in economics and management, and systemically designs multi-dimensional experiment teaching contents of economics and management. And then this paper innovates diversified experimental teaching methods and cross-border organizational forms in teaching, and finally constructs experimental teaching platform, improve the guarantee system of experimental teaching management. In such ways, reform and innovation of management professional talent training is achieved. This system emphasizes on the integration of multi-disciplines and cultivation of students' creativity and overall quality, which serves as an effective approach for the Economics and Management College in Beihang University to produce qualified inter-disciplinary talents.

The experiment teaching system mentioned above has been applied in the Economics and Management College in Beihang University for four years, and helps formulate an experiment teaching mode in economics and management of which is featured with harmoniously development of knowledge, capability and quality and with mutually promotion in study, experiment and innovation. The significant results of the experiment have been greatly recognized and shed lights on. As a result, this system comprehensively enhances teaching and learning quality as well as faculty's capability, creates a virtuous cycle in teaching and learning, and effectively promotes the disciplinary development.

\section{References}

[1] Ellington H., Fowlie J., Gordon M. Using Games and Simulations in the Classroom: A Practical Guide for Teachers. Routledge, 2013

[2] Keys B., Wolfe J. 1990. "The Role of Management Games and Simulations in Education and Research," Journal of Management, 16(2): 307-336

[3] Han Xiaoting, Niu Li. Enterprise resources planning sand table training for engineering students [J]. Applied Mechanics and Materials, 2012, v 121-126: 825-829.

[4] Pasin F., Giroux H. 2011. "The Impact of a Simulation Game On Operations Management Education," Computers \& Education, 57(1): 1240-1254

[5] Xiaoting Han, Li Niu. Constructing Virtual Business Environment Simulation Platform for Multi-Major of Economics and Management in Higher Education [A]. Proceedings of 2013 International Conference on Cyber Science and Engineering [C]. Guangzhou, China, December 14-15, 2013. 